\title{
DE FADAS A ANDROIDES: a cientifização do imaginário mágico popular ${ }^{1}$
}

\author{
Taísa Siqueira²
}

\begin{abstract}
Resumo: O artigo pretende colocar em tela relações entre a ideia de magia e de ciência e observar uma possível cientifização do imaginário popular no sentido de uma substituição da solução mágica por uma possibilidade de avanço técnico científico futuro. Para tanto é feito breve paralelo entre algumas produções literárias e cinematográficas de contos de fadas e ficção científica.
\end{abstract}

Palavras-chave: Conto de fada, ficção científica, magia, ciência, imaginário.

Abstract: The article establishes relation between the idea of magic and science and observes a possible cientifization of the popular imaginary involving a possible replacement of the magic solutions by a future technical and scientific progress idea. It is thus made a brief parallel between some literary and film productions of fairy tales and science fiction.

Keywords: Fairy tale, science fiction, magic, science, imaginarium.

\section{Introdução}

Quando pensamos em contos de fadas é normal que voltemos nossa memória à ideia de contos infantis, pueris e inocentes. Porém, ao estudarmos acerca da história de muitos desses contos descobrimos em suas raízes contos nada gentis tampouco pedagógicos. O que observamos são narrativas populares destinadas não a crianças especificamente, mas a pessoas de maneira geral, adultos e crianças de todas as idades - isso quando há percepção desse conceito, ou sentimento, de infância. Esses contos habitaram e ainda habitam o imaginário popular em todo o mundo. Nos atendo à realidade ocidental, levantamos sobre a temática alguns pontos centrais para uma discussão inicial: o imaginário, a relação entre magia e ciência; a consideração de alguns representantes da produção literária e cinematográfica envolvendo a temática e a constante recuperação de tradições em projeções futuras. Para costurar esses pontos, consideraremos: as entrevistas e a dinâmica com o grupo focal desenvolvidas pelo grupo de pesquisa Conexões Maquínicas ${ }^{3}$; os contos de Pinóquio e

${ }^{1}$ Trabalho apresentado no Seminário “Objetos técnicos, ficção científica e transformação social” na PUC Minas, Coração Eucarístico, em 15 de junho de 2016.

${ }^{2}$ Mestra pelo Programa de Pós-graduação Stricto Sensu em Comunicação Social da PUC MG, taisasiq@gmail.com. Formada também em Comunicação e integra o Grupo de Pesquisa "Conexões Maquínicas", na PUC Minas.

30 projeto "Objetos técnicos, ficção científica e transformação social: investigação dos processos subjetivos implicados com as mudanças tecnológicas" consiste de pesquisa acerca dos modos de afetação entre o homem e a tecnologia. É desenvolvido, com apoio da FAPEMIG, pelo grupo de pesquisa Conexões Maquínicas 
de Cinderela sendo ambos considerados clássicos de fada; e algumas produções cinematográficas de ficção científica que retomam esses contos - valores, conceitos e ideais já apresentados nesses clássicos infantis.

O presente artigo propõe reflexões acerca do quão intricados estão valores e devaneios antigos e contemporâneos no imaginário ocidental, e de como eles são expostos nas diversas expressões culturais ao longo do tempo. As tecnologias são atualizadas no imaginário, mas nem tanto os devaneios que o alimentam, assim, de marionete a androide, de Gata Borralheira a ciborgue, atualizamos o formato, mas nossos desejos costumeiramente permanecem ligados a uma espera de algo como a varinha de condão - de uma fada madrinha, palavras mágicas ou mesmo de uma nova tecnologia - que transforme o que parece ser impossível. Freud sugere que são os devaneios ou fantasias que alimentam a produção do escritor criativo, sendo o devaneio ou a fantasia um "sonhar acordado". Nesse chamado devaneio pode haver uma suavização ou transmutação de um desejo íntimo para apresentação deste a uma outra pessoa, a um observador. Assim, no sonho noturno ${ }^{4}$ e na fantasia ou devaneio há a necessidade de transformar o desejo oculto em algo assumível, seja para si próprio seja para o outro e, para atender a essa necessidade, alguma distorção da coisa - do objeto de desejo ou da situação em que ele se apresenta - é feita. Essa distorção se dá a partir de elementos por vezes fantásticos, impossíveis, deslocados ou aparentemente sem sentido, ou ainda, envoltos em contexto imaginário que justifique ou suavize o desejo, e torne-o suficientemente interessante para ser compartilhado pelo outro, como se vê na citação:

O indivíduo que devaneia oculta cuidadosamente suas fantasias dos demais, porque sente ter razões para se envergonhar das mesmas [...] mesmo que ele comunicasse para nós, o relato não nos causaria prazer. Sentiríamos repulsa, ou permaneceríamos indiferentes ao tomar conhecimento de tais fantasias. [...] $\mathrm{O}$ escritor suaviza o caráter de seus devaneios egoístas por meio de alterações e disfarces e nos suborna com o prazer puramente formal, isto é estético, que nos oferece na apresentação de suas fantasias.”. (FREUD, 1976. p.157-158).

Essa distorção estética do desejo do escritor criativo, como traz Freud, provocaria um prazer formal relacionado à beleza do texto ou da coisa transformada. Mas se o estético for considerado aqui relacionado não apenas à ideia de beleza, mas à sensação, ligando a palavra à sua raiz aisthésis: percepção ou sensação, o sentimento, os sentidos do autor seriam também

(https://conexoesmaquinicas.wordpress.com/). O grupo pesquisa os modos de afetação entre o homem e a tecnologia e uma de suas linhas de investigação busca problematizar relações entre os seres humanos e as máquinas através da literatura e do cinema de ficção científica.

$4 \mathrm{O}$ autor relaciona o devaneio aos sonhos noturnos afirmando-os como sendo da mesma lógica. 
experienciados pelo leitor e o caráter estético-estésico da obra estaria na capacidade do autor de, a partir da obra, afetar o leitor. O efeito estético assim provocado pelo conto clássico ou pelo filme de ficção científica estaria, portanto, relacionado a um desejo "oculto", que mesmo com o passar do tempo ${ }^{5}$, permaneceu forte habitando o imaginário ocidental. Considerando que "a vida dos homens e das sociedades é, constantemente, submetida aos impulsos do imaginário, às imagens encarnadas nas artes (pictóricas, cinematográficas, entre outras) e nas construções mentais coletivas e individuais" (LEGROS et al, 2007, p.10) a busca pela compreensão desse imaginário e das mudanças nele possibilitam compreensão mais ampla do processo comunicativo que o perpassa, que dele se alimenta e que também o fomenta.

\section{Imaginário, Magia e Ciência}

Entre as construções mentais coletivas que podemos observar nas obras aqui escolhidas para breve análise, reforçamos a presença da figura da magia, que, com o passar do tempo, se tecnologiza para tornar-se racionalmente possível em um contexto futurístico, cumprindo com o objetivo de subornar esteticamente leitores e espectadores com uma “magia” possível. Nos contos clássicos de Pinóquio e de Cinderela, amplamente difundidos em versões adocicadas - pelos estúdios Disney, há a presença de alguma fada, ente com poderes especiais para mudar a natureza das coisas. Quando pensamos em transformação da natureza das coisas podemos exemplificar com o poder de transformar um boneco de madeira em um menino de verdade, uma jovem excluída pela família e vestida em farrapos em bela dama - com todos os atributos visuais necessários para ser aceita na alta sociedade local, de maneira a praticamente igualar em termos de importância e valor existencial a situação social da garota à ela enquanto ser, à natureza dela enquanto indivíduo. Mantendo o paralelo com o Pinóquio, ambas as figuras são manipuladas pelas circunstâncias para serem algo que não são. A magia que transforma objetos em outros, que permite o surgimento do sentimento de auto aceitação e a concretização do desejo de reconhecimento externo, recupera um sonho antigo de domínio da natureza das coisas, inclusive da própria natureza, se é que podemos colocar nesses termos, mas em resumo remete ao desejo pelo poder. Sendo esse poder algo a ser aplicado na transformação das circunstâncias do cotidiano dos personagens ficcionais da

5Mais de um século depois do aparecimento da obra escrita de Pinóquio (1883) é lançado I.A. Inteligência Artificial (2001). Dez anos depois de I.A. é lançada Eva: Um novo começo (2011) que também trata de uma menina androide criada como menina "de verdade". 
narrativa fantástica ou de fadas como consideramos aqui inicialmente. Para pensar acerca do tema, trazemos a reflexão de J. Bronowski envolvendo magia e ciência.

$\mathrm{O}$ autor considera duas maneiras de pensar a magia: a primeira como uma percepção antiga de um conhecimento da natureza, de palavras ou gestos que permitiriam ao indivíduo o domínio, no sentido de uma subjugação da natureza à sua vontade:

[...] até o ano de 1500 qualquer tentativa para obter poder a partir da natureza tinha inerente a si a ideia de que só podia conseguir-se isso se se forçasse a natureza a ir contra a sua vontade. A natureza tinha que ser subjugada, e a magia era uma forma de palavras, ações e imagens que forçavam a natureza a fazer algo que, por si própria, ela não faria. (BRONOWSKI, 1986, p. 32).

Essa ideia de magia posteriormente é relacionada pelo autor à ideia de magia negra ${ }^{6}$ ou velha magia. Em contraposição a essa "velha magia", nos termos do autor, surgiria o que ele chama de "magia natural" que envolveria um domínio da natureza, não mais no sentido de colocá-la a serviço da vontade do indivíduo, mas no sentido de conhecer melhor suas leis e explorá-las a fim de obter um bem, como se vê quando o autor afirma:

[...] Ora isto é um conceito muito importante que se desenvolveu entre 1500 e 1550 - a noção de que existe sim uma magia, mas uma magia natural, uma magia branca. Ninguém sabe muito bem como ela funciona, mas ela tenta extrair do Universo as suas próprias harmonias para nosso bem. E cá estamos nós no caminho que conduz à ciência tal como entendemos. (BRONOWSKI, 1986, p. 42).

Enquanto na perspectiva da velha magia haveria a oposição entre anjos e demônios, na magia natural o Universo em sua completude seria a própria face harmoniosa de Deus. Enquanto, para o autor, na velha magia a crença era de que se conseguiria fazer a natureza atuar contra sua vontade, na magia natural busca-se observar a harmonia da natureza para fazer com que trabalhe em correspondência com o desejo humano (1986, p.44). O autor considera também as percepções de outros teóricos que observam na magia o princípio de muitas ciências, como a química na alquimia, e não os nega mas indica que seriam perspectivas distintas da que ele propõe $\mathrm{e}^{7}$. $\mathrm{O}$ autor diferencia, quase que por definição, esses

6É notório, no uso do termo "magia negra" pelo autor para denominar a prática, algum juízo de valor expresso por Bronowski que, ainda na década de 80 , denota uma classificação de atitudes como conectadas a uma percepção de menores, ultrapassadas ou mesmo negativas, se considerarmos a carga histórica e cultural do termo. Isso porém em nada desabona a contribuição de seu raciocínio para o desenvolvimento deste trabalho e por isso aqui o adotamos e optamos também pelo termo "Velha Magia" também utilizado pelo autor para designar o mesmo conceito.

7Apesar de concordar com as observações daqueles que relacionam a alquimia com a ciência, Bronowski se debruça sobre a "atitude que tinham relativamente ao modo como o Mundo funciona e como faremos que ele obedeça, e de modo algum sobre as suas descobertas relativamente ao modo como se fundia o metal ou como se 
dois momentos da magia, indicando também uma ligação entre a magia e a ciência, apesar de partir de um ponto de observação distinto, visto que aponta coincidência entre "morte" da magia o nascimento da ciência.

Essa ligação entre magia e ciência é aqui retomada, não em completa concordância coma as ideias do autor - na medida em que aqui não afirmamos o fim efetivo do que ele chama de velha magia, nem fazemos juízo de valor acerca de quaisquer que sejam os rituais religiosos ou místicos de matrizes culturais diversas - a retomada é feita em decorrência da consideração de um possível berço comum entre magia e ciência. Esse ponto de encontro é retomado aqui, não considerando os anos 1500 como fez Bronowski ao dizer da explosão da ciência moderna coincidindo com o que ele chamou de morte da magia, mas sim partindo da ficção científica como uma maneira contemporânea de ressuscitar em alguma medida a magia. A ficção científica pode ser considerada como expressão do desejo de manter vivo o fantástico mesmo considerando toda a ciência já descoberta, retomando assim a transformação e domínio da natureza no sentido da "magia natural". Essa magia natural ou o desejo por um poder a princípio impossível encontraria alguma vazão na ficção científica, mas em um contexto de maior valorização da ciência em detrimento de crenças e heranças culturais ainda obscuras. Sem intencionar uma psicologização ou mesmo uma teoria universalista envolvendo a produção cultural, ousamos afirmar que não há como negar que o fascínio pela magia nos termos de uma "tecnologia sem ciência" (1986, p.21) persiste ainda hoje, haja vista a permanência e a constante retomada e renovação de temáticas fantásticas e de bruxaria na literatura de grande impacto comercial como Harry Potter, O aprendiz de feiticeiro e muitos outros títulos literários, produtos cinematográficos e de televisão. A ficção científica, apresentando não só reflexos dos avanços científicos, como servindo de inspiração para o desenvolvimento da ciência também permite vasão e expansão do imaginário e de expressão dos mais diversos desejos e medos ocultos em devaneios fantásticos, científicos ou maravilhosos.

O imaginário - esse fenômeno que "circula através da história, das culturas e dos grupos sociais [...] alimenta e faz o homem agir". (LEGROS et al, 2007, p.10) - é produto do

efetuava esse processo no trabalho metalúrgico. [...] Não há menor dúvida de que relativamente a qualquer área científica particular que hoje exista, se podem encontrar vestígios em alguma fantasia da Idade Média. [...] Mas é minha opinião que essas continuidades dão uma perspectiva falsa do grande limiar de que provém a explosão da ciência moderna. E eu poria isso com toda simplicidade: não sei se a ciência nasceu antes de 1500 (embora eu creia que não) mas sei que, misteriosamente, a magia morreu de fato depois de 1500" (BRONOWSKI, 1986, p. $33)$. 
pensamento mítico. Este, por sua vez, é expresso por imagens simbólicas organizadas de maneira dinâmica, e funciona sob o princípio da analogia, que "determina as percepções do espaço e do tempo, as construções materiais e institucionais, as mitologias e as ideologias, os saberes e os comportamentos coletivos." (LEGROS et al, 2007, p.10). Considerar, assim, a dimensão mítica na sociabilidade, na elaboração e sustentação do imaginário, parece, no contexto deste trabalho, profícuo. Acerca da relação do mito com algumas narrativas tradicionais trazemos à luz parte do pensamento do historiador de religiões e mitólogo Mircea Eliade (1972).

Para o autor o mito permaneceria muitas vezes de forma superficial no conto atuando sobre o ser humano e social. Como uma espécie de caroço semântico, que poderia ser sentido nas diversas versões das histórias, esse fundo comum - mágico ou sagrado ligado ao mito permanece entremeado nos contos clássicos infantis e outras narrativas tradicionais diversas. Nesse ponto recuperamos a ideia de magia natural, ou magia branca advinda de um neoplatonismo, observada por J.Bronowski em que é feita a referência de um universo natural e em equilíbrio e harmonia como a própria face de Deus (BRONOWSKI, 1986 p.38). A aproximação das duas ideias de um fundo mítico e sagrado em contos tradicionais de uma magia em harmonia com o universo que seria a própria face harmônica de Deus nos parece interessante na medida em que, a partir de observações distintas, os dois autores identificam um gesto de aproximação com um sagrado. A magia natural acabou porém resultando, de acordo com Bronowski (1986 p.44), na negação à ideia de magia e reconhecimento de uma lei da natureza que seria enfim a aproximação da ciência. Observamos aqui novamente o fundo comum, mágico e mítico entre contos tradicionais e clássicos infantis e a ciência. Relacionando esse plano de fundo com as descrições envolvendo o imaginário expostas aqui podemos dizer que essa base mítica passaria também a compor, com considerável importância, nosso processo de socialização iniciado na infância e afetaria a estrutura de nossos sentimentos, personalidades e até de raciocínio lógico.

Voltando a Eliade acerca da importância mítica dos contos:

Poder-se-ia quase dizer que o conto repete, em outro plano e através de outros meios, o enredo iniciatório exemplar. O conto reata e prolonga a "iniciação" ao nível do imaginário. Se ele representa um divertimento ou uma evasão, é apenas para a consciência banalizada e, particularmente, para a consciência do homem moderno; na psique profunda, os enredos iniciatórios conservam sua seriedade e continuam a transmitir sua mensagem, a produzir mutações. Sem se dar conta e acreditando estar se divertindo ou se evadindo, o homem das sociedades modernas ainda se beneficia dessa iniciação imaginária proporcionada pelos contos. Caberia então indagar se o 
conto maravilhoso não se converteu muito cedo em um "duplo fácil" do mito e do rito iniciatórios, se ele não teve o papel de reatualizar as "provas iniciatórias" ao nível do imaginário e do onírico. [...] o que se denomina "iniciação" coexiste com a condição humana, que toda existência é composta de uma série ininterrupta de "provas", "mortes" e "ressurreições", sejam quais forem os termos de que se serve a linguagem moderna para traduzir essas experiências (originalmente religiosas). (ELIADE, 1972, p.141).

A ideia de Eliade parece trazer à tona uma percepção idealista ou universalista dos contos, na medida em que abre precedente para o pensamento de que o mito, ou mesmo o conto clássico, traz consigo algo da essência humana e universal. Esse entendimento é abordado aqui com cautela, visto que o conto é também considerado como documento histórico em que as variadas gerações e civilizações que com ele tiveram contato puderam imprimir neles seus valores e ideologias. Ainda que a possibilidade da origem primordial mítica ou de valor ligado à magia de alguns contos não esteja sendo descartada, a conexão emocional dos indivíduos com eles é de maior importância nesse momento. Considerando a possível valorização mítica de narrativas tradicionais, ou dos chamados clássicos infantis, e essa ideia de mito com uma questão possivelmente sagrada, ou sacralizada pelos indivíduos ao longo do processo de socialização, fazemos aqui uma ponte com algumas temáticas comuns nas narrativas tradicionais que ainda circulam na sociedade ocidental: A constante presença e recuperação do desejo do domínio de si e da natureza segue em consonância com a linha de pensamento de Eliade no sentido de recuperação de provas iniciatórias e de superação e auto-superação, incluindo também um desejo de se igualar a uma virtude suprema, algo como "querer ser Deus", ou ainda de superar a figura de Deus, de superar a condição meramente humana para ter algum poder mágico ou criador ou mesmo um poder sobrenatural sobre si próprio, sobre seu destino. Poder este que em diversas circunstâncias, ficcionais ou não, muitas vezes pode parecer impossível ao indivíduo sem uma intervenção mágica.

\section{Sobre o "brincar de Deus" da magia do conto ao sonho de criar um novo humano.}

A necessidade da magia para a mudança no indivíduo é elemento importante no conto de Pinóquio, um boneco de madeira vivo e autônomo que não é afeito ao trabalho tampouco ao estudo. O que ele mais quer é ser um menino de verdade, mas caba sempre se deixando 
levar - o que é bastante conveniente a uma marionete - por quem encontra pelo caminho, se deixando conduzir sempre ao caminho do prazer, da facilidade e da irresponsabilidade. O desejo de Pinóquio de ser dono de seu próprio destino, só é efetivamente alcançado quando abraça, por amor à família, a responsabilidade. A moralidade claramente expressa no conto de 1883 de Carlo Collodi, recuperada e reafirmada na animação Disney de 1940 se reveste de magia e pode ser compreendida de duas formas, uma otimista e outra pessimista. A visada otimista seria a compreensão, com base no conto, de que tudo é possível, já a pessimista envolveria colocar na magia um valor de realidade efetivamente inatingível no caso do conto, algumas coisas, como a transformação de Pinóquio só são possíveis com intervenção direta superior e mágica além de envolver a exigência de provas a serem vencidas pelo personagem. Assim, ao mesmo tempo, em que o boneco se torna um menino por ação da fada azul, ele também obtém seu novo status por mérito próprio. Da mesma maneira com que é possível identificar nas abordagens do conto um reconhecimento a uma instância superior de poder, também é possível verificar a valorização da persistência da ação do indivíduo.

A intenção aqui não é fazer uma análise considerando as representações diversas que um boneco de madeira com vontade própria movido pelo prazer pode ter, nem as referentes à ideia de um menino "de verdade", tampouco de desconsiderar a importância dessa análise para fins distintos, mas o que propomos aqui é a observação da representação da magia, como uma esfera de poder, tanto de uma possível "velha magia" - identificável na "madeira viva" em que foi entalhado o boneco e na existência da fada - quanto de uma "magia natural" que pode ser observada na própria transformação das atitudes e do caráter de Pinóquio como a magia possível, na mudança de um ser pouco sensível, acostumado aos prazeres e à ignorância em um ser amoroso, responsável e dotado de virtude. Enquanto a ideia de velha magia coloca o poder em um ente terceiro e pede uma interpretação mais literal, a de magia natural coloca o poder no próprio sujeito, o poder de entender as leis "naturais" e trabalhar com elas para seu benefício. Estando assim a figura de um Deus ou de um agente superior transformador ora depositada na fada ora na naturalidade da transformação do indivíduo. Quando depositada no indivíduo que age de acordo com a natureza e dela se beneficia, de alguma maneira a magia do conto se aproximaria da ciência nos termos de Bronowski na medida em que acabaria acercando-se dela pelo reconhecimento de uma lei natural.

$\mathrm{O}$ avanço da ideia de magia natural na contemporaneidade e a aproximação dessa magia com a ideia de desenvolvimento da tecnologia podem ser observados na versão 
robótica de Pinóquio. O boneco de madeira que quer virar um menino de verdade é recuperado, na produção de 2001 dirigida por Steven Spielberg, que conta a história de um robô humanoide, ou melhor, um androide, dotado de inteligência artificial, incluindo uma capacidade de "amar" programada e irreversível. A versão Sci-fi da marionete também deposita suas esperanças na magia da fada azul de Pinóquio que ele passa a acreditar ser real quando escuta o conto clássico. David, o menino androide faz de tudo para obter a felicidade de amar e ser amado, o "brincar de Deus", neste filme, fica a cargo dos indivíduos, visto que a magia ligada ao campo feérico ou aos contos maravilhosos não se apresenta como factual. Partimos da possibilidade aqui de que o brincar de Deus, antes relacionado à conferência de poderes extraordinários a gênios, fadas, ou mesmo à própria natureza imbuída de profunda ligação e subserviência a um determinado indivíduo, passa a povoar o imaginário popular, porém com ar mais cientificizado em outras instâncias. No filme, cabe à própria inteligência artificial no seu mais alto grau de evolução - já completamente desvinculada e independente da humanidade, a qual prece ter perecido no fim do longa-metragem - conferir David a falsa, porém real - já que se trata de programação de dados e manipulação genética - memória e experiência de retribuição do amor de mãe, e assim, numa mudança de código a "magia" é feita e o milagre aparece.

Nesse momento cabe iniciarmos a convocação de parte do conteúdo gerado por uma série de entrevistas ${ }^{8}$ executadas pelo grupo de pesquisa Conexões Maquínicas acerca do envolvimento de leitores e espectadores de ficção científica com o gênero. De uma das entrevistas recuperamos aqui o comentário de um dos participantes: "tecnologia suficientemente avançada é indistinguível de mágica" (Trecho de entrevista ${ }^{9}$ ). No momento da afirmação do entrevistado, ele havia sido pedido que enumerasse e descrevesse diferentes objetos técnicos encontrados em contos e romances de ficção científica que não teriam correspondência no "mundo real". A partir do comentário é possível observar alguma circulação da ideia de semelhança entre o conhecimento técnico-científico, a magia ou mesmo

\footnotetext{
${ }^{8}$ Foram entrevistadas algumas pessoas leitoras de Ficção Científica a fim de identificar em que medida há o conhecimento claro de conceitos comuns e caros ao gênero, além de permitir uma visão inicial, um ponto de partida envolvendo alguns aspectos correntes, principalmente da relação ser humano $\mathrm{X}$ máquina. As entrevistas não tinham objetivo de gerar dados quantitativos mas sim qualitativos na medida que geraram conteúdo para possíveis linhas de análise e foram realizadas com base em um questionário desenvolvido previamente e todas as respostas foram gravadas em áudio ou vídeo. Essas entrevistas foram a segunda etapa metodológica da pesquisa a qual focava na abordagem das relações entre ficção científica e processos de subjetivação. Esta etapa citada foi antecedida pela pesquisa bibliográfica e sucedida pela terceira parte do projeto que envolveu a criação de um grupo focal com pessoas que se envolveram afetivamente pela internet, neste momento, porém, concentramos a atenção nas entrevistas com leitores/espectadores de ficção científica.

9 Idem nota 3. Entrevistado: Paulo Milan.
} 
a ideia de milagre. Em desenvolvimento a esse pensamento, a relação de semelhança entre magia, milagre e ciência e ainda considerando o filme I.A. podemos pensar que entre os que brincam de Deus na história estão inicialmente os cientistas que propõem a criação de um androide com inteligência artificial e capacidade de amar e sonhar. Além destes figuraria também a mãe que faz brotar um amor num jogo de palavras, como em um encanto, e, também como em um encanto, os indivíduos de I.A. mais evoluídos ao fim do filme reconstroem a memória do "menino".

Consideramos aqui o elemento do brincar de Deus também por ter sido elemento levantado por outro entrevistado:

[...] a criação, brincar de Deus em ficção científica, as minhas preferências são, primeiro, por aquilo que dá medo, aquilo que é desconhecido né, explorar o desconhecido... é... eu gosto muito dessa temática de brincar de Deus e ver até onde, qual que é o limite, até onde que pode ser tratado, até onde que o cara quer descobrir mesmo alguma coisa, e até que ponto que vai começar a dar problema... (Trecho de entrevista ${ }^{10}$ )

O ponto levantado pelo entrevistado de relacionar o poder científico, inventivo e investigativo à ideia da criação divina ou ao conhecimento divino ou superior nos parece útil por recuperar um aspecto mítico, religioso, mágico em alguma medida, e relacioná-lo à ciência como se houvesse um desejo humano em ser Deus criador e senhor do destino da criatura, mas, ao mesmo tempo, permanecesse o medo da sobreposição da criatura em relação ao criador.

Esse medo, apesar de recorrente nas relações entre humanos e máquinas ou entre o humano e o tecnológico, é algo que parece não encontrar eco em algumas produções contemporâneas que abordam a temática. O romance adolescente Cinder de Marissa Meyer que, de maneira ainda mais objetiva do que a executada em I.A., recupera um conto de fada considerado clássico na cultura ocidental, é um exemplo. O livro traz uma Cinderela ciborgue adolescente que em uma realidade de eras posteriores à contemporânea, em que a Lua já é habitada e que conta com muitos dispositivos técnicos avançados, mas a sobreposição humana se mantém inquestionável, o romance, apesar de pleno de aparatos tecnológicos na prática apresenta a interação face a face como a mais corrente, o que é entendido como um indício da "era" da autora. No conto de fadas cientificizado não há a figura da fada madrinha, de milagres ou coisa parecida mas há uma ciência fantástica que envolve desde a manipulação de

10Idem nota 3. Entrevistado: Raphael Silveira. 
mentes possibilitada pela geração de campos magnéticos, a amigos leais e submissos com inteligência artificial.

$\mathrm{Na}$ cientificização do imaginário popular a Cinderela já não impressiona com carruagem de abóbora, e apesar de ser subjugada e humilhada por ser vista como sendo de classe inferior, ciborgue - visto que mesmo com toda a tecnologia, as máquinas não dominaram o mundo e continuam abaixo do ser humano - tem personalidade forte, inteligência e se opõe, em parte, ao padrão gata borralheira: de plebeia à espera de um príncipe. A Cinder, de Meyer, como é desvelado ao longo do romance, não só já é princesa por direito e não sabe, como já é um ser humano em grau distinto de evolução por ter nascido na Lua. Em acordo com o modelo contemporâneo de princesas que vem se consolidando mais forte e independente, mas sem perder a delicadeza e o sentimentalismo clássico - a autora mistura tecnologia, vidas extraterrestres, príncipes e outras figuras semelhantes às bruxas malvadas dos contos clássicos e "magia" - aqui usada entre aspas em referência à maneira como personagens leigos do livro se referem ao conhecimento e domínio de eletromagnetismo, algo que seria científico. Ao longo da leitura é possível observar que mesmo projetando o imaginário para o futuro, o passado e o presente são o que orientam o enredo. O desejo e o encantamento da magia permanecem, mas, recuperando a ideia de suborno formal a que Freud se refere, ele agora precisa ser travestido de ciência. O desejo de que a magia seja possível se faz premente, e em uma realidade de crescente valorização da ciência $^{11}$, ele muitas vezes se utiliza do conhecimento científico real e suposto circulante no imaginário popular - alimentado não só pelos avanços científicos reais como por toda a literatura e produção cinematográfica de temática de ficção científica - para ter vasão e continuar a ser a alimentado.

Se a necessidade de magia para transformar o status social de um indivíduo denotaria uma possível falta de esperança na transformação social efetiva, a ficção científica já permite a concepção dessa possibilidade, mesmo que como esperança em realidades futuras projetadas, mas que, invariavelmente, acabam refletindo o que há de mais contemporâneo, presente e ordinário nas relações humanas. De alguma forma o real sempre se apresenta nos

11Apesar de recentes investidas políticas contrárias ao avanço de alguns estudos em razão de pressões religiosas no Brasil e em outros países, a valorização da ciência e da filosofia é aqui considerada como crescente na perspectiva ocidental capitalista contemporânea. Há de se considerar também uma recente renovação da valorização e exposição de religiões, misticismos no país e seria interessante estabelecer um paralelo com o berço comum entre o mítico, o mágico e o religioso em relação à ciência. A observação dessa temática é esboçada nesse artigo mas, por limitações de tempo e temática, não será escrutinizada com profundidade. 
contos clássicos, primordiais, na literatura contemporânea, na produção cinematográfica de ficção científica e no imaginário que envolve todas essas e outras expressões culturais e viceversa. A afirmação pode parecer óbvia, mas é muitas vezes negada pela separação didática tradicional entre verdade e ficção - como se não houvesse ficção na verdade humana nem verdade na ficção por nós produzida. Esse binarismo de contraposição é também observado, na oposição entre as ideias de magia e ciência, mas que, como já observado em Bronowski tem berço comum ainda que distinto. Jacqueline Held afirma que "o fantástico nos toca se não for feito apenas de entidades, de seres abstratos" e questiona: "O que é que vivifica o fantástico e vem lhe dar a sua verdadeira densidade, senão a simples vida cotidiana, com seus problemas, sua comicidade, seus ridículos, sua mistura íntima de cuidados, de angústias, de pitoresco, de ternura?" (HELD, 1980, p.28). O posicionamento de Held, na mesma direção do de Freud, indica que o que nos faz sentir tocados pelo fantástico é o que de cotidiano e comum reconhecemos no enredo, mesmo que este seja absurdo.

Quando nos deixamos subornar pelo fator estésico das fantasias do autor criativo reconhecemos naquela fabulação algo de real que ecoa em nós, passamos a cúmplices daquele devaneio. E é basicamente esse o gesto feito por Meyer em Cinder ao projetar no futuro situações por vezes mais ligadas a um passado emocional da autora ${ }^{12}$ que encontra, a julgar pelo sucesso ${ }^{13}$ de vendas do livro em todo o mundo na classificação infanto-juvenil, eco, não só desse passado da autora quanto também do futuro imaginado por ela, em realidades bem distintas ${ }^{14}$. Enquanto os jovens contemporâneos aparentemente tem dificuldades para estabelecer novos relacionamentos face a face, sendo necessária a mediação de algum site, rede ou App que crie situações para a interação social, a adolescente Cinder de Meyer e basicamente todos os personagens (que não se encontram isolados por motivos de doença) se relacionam diretamente, face a face, sendo a comunicação mediada pouco explorada e mas similar com a que temos hoje, mas diferente da que se mostra como tendência para o futuro já plantada e em curso hoje em gerações posteriores à da autora.

Nesse sentido, considerando a ideia de Jacqueline Held (HELD, 1980, p.30), que recorre a Raoul Dubois, para afirmar que "todo livro é documentário no sentido bastante

12A autora, nascida em 1984, se declara "fã de muitas coisas nerds [...] apaixonada por contos de fada desde criança - e não pretende abandonar isso" (MEYER, 2012).

130 livro, publicado no Brasil pela Editora Rocco, já foi traduzido para cerca de 20 países.

14A realidade distinta aqui é afirmada com base em observações empíricas obtidas nas declarações de jovens entre 19 e 24 anos do grupo focal montado pelo grupo de pesquisa que se relacionam ou já se relacionaram afetivamente por intermédio das mais diversas tecnologias, aplicativos etc. 
amplo em que nos informa sobre o coração humano", nos parece válido compreender Cinder como mais um documentário de memória afetiva de toda uma geração que, apesar de se distanciar em muitos aspectos da geração seguinte, ainda encontra lugar no imaginário de adolescentes e jovens de hoje. Held não só reforça Dubois como também complementa a ideia dele ao afirmar que isso poderia ser factual para qualquer narração fantástica, por mais bizarra que seja (HELD, 1980, p.30). O que também nos parece verdadeiro se pensarmos em contos clássicos de forma geral, não só os documentados em livros mas também os orais, as suas variadas versões nas mais diversas mídias incluindo seus hibridismos envolvendo a temática clássica e mágica em véu de ficção científica. Versões, adaptações de novas percepções do mágico, fantástico e bizarro sempre documentam, em alguma medida, um reflexo da realidade.

\section{Referências}

BRONOWSKI, Jacob. Magia, ciência e civilização. Tradução de Maria de Luz Veloso. Lisboa: Edições 70, 1986.

COLLODI, Carlo. As aventuras de Pinóquio: História de um boneco. Tradução de Ivo Barroso. São Paulo: Cosac Naify, 2014.

ELIADE, Mircea. Mito e Realidade. Tradução de Pola Civelli. São Paulo: Editora Perspectiva 1972.

EVA: UM NOVO COMEÇO (Título original: EVA) Dir. Kike Maíllo, Espanha. Paramount Pictures. 2011. 94min.

FREUD, Sigmund. Escritores criativos e devaneios. In: FREUD, Sigmund. Obras completas de Sigmund Freud. Rio de Janeiro: Imago, 1976. v.9. p. 147-158.

HELD. Jacqueline. O imaginário no poder: as crianças e a literatura fantástica. Tradução de Carlos Rizzi. São Paulo: Summus Editorial, 1980.

I.A. INTELIGÊNCIA ARTIFICIAL (Título original: A.I. Artificial Intelligence) Dir. Steven Spielberg, EUA. Warner Bros, 2001. 146min. 
LEGROS, Patrick et al. Sociologia do imaginário. Tradução de Eduardo Portanova Barros. Porto Alegre: Sulina, 2007.

MEYER, Marissa. Cinder. Tradução de Maria Beatriz Branquinho da Costa. Rio de Janeiro: Rocco Jovens Leitores, 2013. 